\title{
É possível fazer física sem filosofar?
}

\section{Is it possible to do physics without philosophy?}

Vinícius Carvalho da Silva ${ }^{1}$

Resumo: Neste ensaio questionamos em que medida é possível fazer física sem filosofar. Nossa ideia é a de que a história da física revela que em todos os tempos, os grandes acontecimentos no interior do campo foram protagonizados por cientistas que não dissociavam a atividade física da filosófica, considerando a análise filosófica como um pressuposto epistêmico da produção do conhecimento científico. O texto, na forma de ensaio, assume uma narrativa compatível com o gênero, menos formal e mais livre.

Palavras-chave: Filosofia da Física. Metafísica da Ciência. Epistemologia. Axiologia. Lógica da Ciência.

Abstract: In this essay we question to what extent it is possible to do physics without philosophizing. Our idea is that the history of physics reveals that at all times, the great events in the countryside were carried out by scientists who did not dissociate physical activity from the philosophical one, considering philosophical analysis as an epistemic assumption of the production of scientific knowledge. The text, in the form of an essay, assumes a narrative compatible with the genre, less formal and more free.

Keywords: Philosophy of Physics. Metaphysics of Science. Epistemology. Axiology. Logic of Science.

Acredito que todo [físico] teórico verdadeiro é uma espécie de metafísico domesticado, não importa o quão puro ele se ache como "positivista". Einstein em "Sobre a Teoria Geral da Gravitação", p. 12.

O filósofo da ciência Lawrence Sklar em Philosophy of Physics (1992) defende que a filosofia da ciência possui duas grandes vertentes: epistemologia da ciência e metafísica da ciência. A epistemologia da ciência trata das questões conceituais e metodológicas da teoria física e seus experimentos, da demarcação e justificação do conhecimento científico, bem como de suas possibilidades e limites. A metafísica da ciência trata da realidade abordada por tais

\footnotetext{
${ }^{1}$ Doutor em Filosofia da Ciência e Teoria do Conhecimento pela UERJ. Professor da Universidade Federal do Mato Grosso do Sul. E-mail: viniciusfilo@gmail.com. Ensaio recebido em 25/03/2020 e aceito em 28/03/2020.

Perspectivas - Revista do Programa de Pós-Graduação em Filosofia da UFT - volume 5, n. 1 - 2020
} 
teorias e experimentos, dos pressupostos metafísicos acerca da natureza da realidade implícitos nas teorias, dos aspectos ontológicos da realidade que constitui o objeto da investigação científica (Sklar, 1992). Estamos de acordo com tais definições de epistemologia e metafísica da ciência, mas acreditamos que a Filosofia da Ciência não se reduz a estas duas "linhas de pesquisa”. Defendemos que além de epistemologia da ciência e metafísica da ciência, também constituem campos de investigação da Filosofia da Ciência:
a. Lógica da ciência
b. Axiologia da ciência ou Ethos da ciência
c. Estética da ciência

A lógica da ciência pode tanto ser compreendida como parte da epistemologia da ciência como ser pensada em sua especificidade. De natureza mais formal, a lógica da ciência trataria da análise lógica dos sistemas fechados de proposições, da consistência dos conjuntos de enunciados de uma dada disciplina, dos axiomas lógicos fundamentais de uma teoria, da verificação dos limites de aplicabilidade de sistemas lógicos à teorias específicas e da elaboração de novos formalismos lógicos compatíveis com os avanços teóricos daqueles sistemas, como a mecânica quântica, para os quais os axiomas das lógicas tradicionais podem não ser aplicáveis.

A axiologia ou investigação do ethos da ciência pode abarcar tanto a dimensão da ética aplicada à ciência (Devemos ou não devemos construir uma bomba atômica? Devemos ou não devemos gerar energia nuclear?) quanto discutir a presença de valores na pesquisa científica. Quais são os valores da pesquisa científica? Historicamente como os físicos defenderam como a ciência deveria ser? A pesquisa em axiologia nesse nível deve possuir uma sutileza tanto hermenêutica quanto histórica para chegar a uma compreensão das diferenças - e possivelmente tensões - entre fatos e valores. A axiologia se interessa tanto pela ciência tal como é feita, do ethos da ciência encarnado em suas práticas sociais cotidianas e locais de produção e, para tanto, deve se aproximar ao máximo das pesquisas históricas e sociológicas, quanto pela ciência como deveria ser, o que requer uma atenção minuciosa às ideias, reflexões filosóficas, textos, pronunciamentos, entrevistas e demais materiais que contenham a concepção axiológica dos próprios cientistas em relação à ciência. Neste caso, é de grande importância verificar não somente quais valores os praticantes de ciência atribuem ao trabalho de pesquisa, mas, sobretudo, como respondem a questão "qual é o valor da ciência?”. 
Por fim, a estética da ciência poderia ser igualmente pensada como constituinte da epistemologia ou mesmo da metafísica e até mesmo da lógica, mas pode igualmente constituir um campo específico da filosofia da ciência. É a área que trata da questão da beleza das teorias científicas, e de conceitos e pressupostos afins, como elegância, "harmonia" e simplicidade. O filósofo da ciência, mesmo que em sua pesquisa venha a se debruçar com mais afinco em uma ou duas dessas áreas, deve possui uma visão do todo, e tratar da ciência como um ente complexo multidimensional ou polimodal, isto é, que possui múltiplos modos ou "dimensões" de organização e ação. Não acreditamos, por exemplo, na possibilidade de uma filosofia da física arrojada sem o recurso à História e Historiografia das Ciências. Para o entendimento filosófico de uma área da física, como por exemplo, a mecânica quântica, será necessário levantar questões em diversos campos: metafísica, epistemologia, lógica, axiologia e estética, e será necessário fazê-lo em diálogo com a História:

a. Questões metafísicas: É a realidade objetiva? O que são as partículas elementares? O que significa dizer, em sentido ontológico, que os eventos quânticos não são causalmente determinados? Qual é a ontologia das partículas hipotéticas, das entidades teóricas e dos inobserváveis no sistema de enunciados de mecânica quântica (MQ)? É a incerteza uma propriedade ontológica da natureza? Qual é a natureza da probabilidade dos eventos quânticos? Os inobserváveis são entidades teóricas ou entes físicos? Entidades matemáticas puramente abstratas podem ser os fundamentos ontológicos de uma teoria física? O que é o espaço? Quais os pressupostos ontológicos de uma teoria física?

b. Questões epistemológicas: O conhecimento dos sistemas quânticos é no máximo probabilístico? O que significam, no escopo da mecânica quântica, os conceitos de "matéria", "espaço", "tempo" etc. O que podemos conhecer? Conhecemos a natureza, o real, tal como é, independente de nós, ou tudo o que podemos conhecer são nossas interações com a natureza? Como a linguagem comum pode ser imprescindível para a descrição dos sistemas quânticos? É possível comunicar coerentemente os eventos quânticos por meio da linguagem comum? Quais os critérios de verdade no escopo da MQ?

c. Questões lógicas: Os axiomas, ou princípios, da lógica clássica, se aplicam aos sistemas de proposições da mecânica quântica ou a mecânica quântica requer a formalização de uma lógica quântica? Podemos falar de identidade entre 
entidades como elétrons? A dualidade quântica impõe limites aos princípios de não contradição e terceiro excluído? O que significa a simplicidade lógica de uma teoria física? Quais a "regras do jogo" das relações entre os enunciados de mecânica quântica? Como são formados seus conceitos primários ou fundamentais? São as teorias físicas sistemas lógicos de axiomas, teoremas e enunciados teóricos e empíricos? Quais os princípios lógicos fundamentais de tais sistemas? O que são a simplicidade e a consistência lógica das teorias físicas?

d. Questões axiológicas: Como os formuladores da mecânica quântica responderam pela questão do valor da ciência, quais valores (princípios axiológicos) eles acreditavam que animavam seus trabalhos de pesquisa, e como suas concepções acerca do valor da ciência e seus princípios axiológicos impactaram a construção de seu trabalho teórico? Como eles praticavam a ciência? Quais eram suas práticas cotidianas e como suas interações sociais impactaram em sua pesquisa? A mecânica quântica resultou de um grupo com um ethos próprio? Qual?

e. Questões estéticas: Podemos dizer que a beleza é um critério de verdade para a teoria? Qual é o conceito de beleza em questão? Por que os elementos teóricos ou experimentos de mecânica quântica são belos? A mecânica matricial e a mecânica ondulatória são matematicamente equivalentes, mas são igualmente "belas" ou "elegantes"?

As questões não esgotam o hall de objetos tratados pela filosofia da física. Na medida em que nos debruçamos sobre objetos mais específicos, questões mais esotéricas vão surgindo. No momento, por exemplo, trabalhamos em uma interpretação da função heurística do princípio da relatividade de Galileu e das transformações de Lorentz na construção da Teoria da Relatividade Especial e Geral. O objetivo é investigar como o princípio da relatividade e as transformações de Lorentz são utilizados por Einstein como postulados lógicos para toda e qualquer teoria física, isto é, pressupostos teóricos que a física deve assumir para se aproximar da "unidade lógica do mundo" (EINSTEIN. 2017, p. 68).

Já vimos, em linhas muitos gerais, como podemos compreender a filosofia da física. Muitos dos filósofos da física são físicos. Físicos e filósofos. Mas queremos dar um passo além e perguntar se os físicos (não alguns, mas em geral) são filósofos, ou se deveriam ser. É possível fazer física sem filosofar? Não se trata de perguntar se uma filosofia da física é possível, seja 
ela feita por filósofos profissionais, ou por físicos, mas se a física é possível sem a filosofia. $\mathrm{O}$ problema é sutil e estrito: Poderá alguém fazer física sem que necessariamente tenha que fazer filosofia? A criação da teoria física pressupõe uma atividade filosófica em ao menos um desses níveis acima descritos?

Ora, a resposta para tais questões pode variar imensamente, dependendo do modo como compreendemos o que seja a física. Para aqueles que têm um entendimento tecnicista e utilitário da ciência, certamente a física não possui nenhuma relação necessária com a filosofia. A física, como expressão da técnica, se restringiria a uma tentativa de interferir no curso do mundo, em conhecer a fenomenologia da natureza para obter controle sobre seus eventos, fazendo previsões, manipulando recursos, produzindo tecnologias. Óbvio que isso levanta uma série de problemas filosóficos, de modo que uma filosofia da física continuaria sendo importante. A filosofia não seria algo intrínseco e estrutural da própria física. Os filósofos analisariam a física "de fora", mas os físicos não fariam filosofia "de dentro".

Que a física deva, necessariamente, ser reduzida a tal dimensão tecnicista e utilitária, nos parece um clichê injustificável. Para aceitá-lo é preciso desconhecer, ou decidir ignorar, toda a complexidade filosófica da ciência, não levando em conta sua densa história. Estou entre aqueles que entendem que em seu núcleo esotérico e heurístico, a ciência, e no caso específico a física, é uma atividade epistêmica baseada em pressupostos metafísicos e princípios axiológicos, que produz teorias que a rigor são sistemas lógicos de enunciados, e que enfrenta e levanta problemas éticos e estéticos. Pensamos que aqueles físicos que participam da construção epistêmica de seu campo de saber, devem, em diversos momentos, lidar com questões metafísicas, epistemológicas, lógicas, axiológicas e estéticas. Isto é, os físicos, sobretudo nos períodos de análise e interpretação dos fundamentos da física, de criação e interpretação de novas teorias, de análise e refutação de teorias consagradas, de revisão ou modificação conceitual, se veem obrigados a fazer filosofia da física.

Uma física que perde conteúdo filosófico e que se reduz a instrumento da técnica, uma física que vê sua substância filosófica decrescer, que deixa de estar consciente de seus pressupostos ontológicos e epistemológicos, uma física de técnicos especialistas movida por interesses utilitários, é uma "física" que se perde enquanto ciência, que perde vitalidade para superar crises e promover "revoluções". Certamente, não foi uma física desse tipo que foi produzida por Galileu, Newton, Herschel, Hertz, Maxwell, Mach, tampouco por Boltzmann, Planck, Einstein, Bohr, Heisenberg, Schrödinger e tantos outros. Qualquer um que se esforce minimamente em conhecer tais autores constatará que todos consideravam a física e a filosofia 
como atividades irmanadas e indissociáveis, e todos escreveram fartamente sobre os problemas filosóficos enfrentados em seu trabalho científico.

É possível fazer física sem filosofar? Seria ótimo que tal resposta fosse dada por um físico, ou por muitos físicos, se possível. Se por física entendemos uma atividade epistêmica cujo propósito é conhecer a realidade, ou como disse Einstein em Física e Realidade, conhecer "a unidade lógica do mundo", a resposta será negativa. Para Einstein a Física exige atividades filosóficas de seu praticante. "Por que então não deveria o físico deixar ao filósofo o encargo de filosofar?", se pergunta Einstein (EINSTEIN. 2017, p. 65). Por que é preciso ousar pensar? Por que não basta apenas medir, tomar notas, mensurar e calcular? Porque o físico não possui tal escolha caso sua tarefa seja fazer com que a física avance por novos domínios, expandindo as fronteiras do conhecimento. "Numa época como a atual, quando a experiência nos obriga a procurar um fundamento novo e mais sólido”, em uma época de crise em que uma nova física está em gestação, "o físico não pode simplesmente ceder ao filósofo a consideração crítica dos fundamentos teóricos" (EINSTEIN. 2017, p. 65). O entendimento de Einstein ecoará em Kuhn. Nos momentos de ciência extraordinária, o recurso à filosofia é fundamental (Kuhn, 2001).

Se o físico deve filosofar, se não deve deixar ao filósofo a exclusividade de fazer filosofia, então o filósofo não possui lugar na física? Ora, como o físico faz filosofia senão dialogando fortemente com a tradição filosófica, pensando e repensando problemas filosóficos, e aplicando recursos filosóficos à física? Em seu exercício filosófico, Einstein teve de dialogar com Espinosa, Kant, Hume, Schopenhauer, entre outros. Para que o físico possa filosofar, deve haver filosofia, e para que haja filosofia, são necessárias filósofas e filósofos. O lugar do filósofo na física está triplamente assegurado: Primeiro, o filósofo está presente enquanto físico. Os próprios físicos, como Einstein, podem (e para Einstein, “devem”) ser filósofos. Segundo, os físicos filósofos em seu exercício de revisão conceitual dos fundamentos da física, elaboração de experiências de pensamento, criação de conceitos, interpretação das teorias físicas, reflexão sobre os problemas metafísicos, epistemológicos e lógicos da física, recorrem à tradição filosófica, avaliando em que medida o pensamento filosófico pode contribuir para entendermos e modificarmos a física, ou em que medida a física pode contribuir para entendermos e modificarmos o pensamento filosófico. Uma terceira maneira de pensarmos o lugar do filósofo na física é refletindo sobre o tipo de atividade que desenvolvemos, a filosofia da física. Filósofos da física e físicos podem manter estreito e constante diálogo, colaborando entre si. 
O que pretendemos mostrar na última parte desse brevíssimo ensaio é que físicos como Planck, Einstein, Heisenberg e Schrödinger, conhecidos justamente como físicos filósofos, pensaram que o próprio valor da ciência é filosófico. Esses fundadores da física relativística e da mecânica quântica defenderam que é justamente a atitude e os problemas filosóficos que animam o núcleo intelectual da ciência.

Quando analisamos a vida e a obra de dezenas de físicos que participaram da fundação da física relativística e da teoria quântica, que depois se consolidaria por meio da mecânica quântica, dois traços comuns saltam aos olhos. Todos tiveram uma boa formação filosófica, conheciam a tradição grega, foram leitores dos modernos e estavam familiarizados com questões metafísicas, epistemológicas e éticas. Há textos de tais físicos discutindo as obras de Platão, Aristóteles, Galileu, Descartes, Kant, Hume, Schopenhauer etc. Além de leitores de filosofia, foram escritores. Seus escritos filosóficos são verdadeiramente volumosos. Se somarmos toda a produção filosófica de Schrödinger chegaremos a centenas de páginas distribuídas em diversos livros, como A natureza e os gregos e Ciência e humanismo. Heisenberg escreveu ainda mais, e discutiu problemas de ontologia e epistemologia em obras como Física e Filosofia e A Parte e o Todo. Planck, Einstein, Bohr, Pauli, Weizsäcker também possuem extensa produção filosófica.

Max Planck (2012) pensava que a ciência possui uma dimensão metafísica inevitável. Toda teoria física assume pressupostos ontológicos e epistemológicos. Algum tipo de combinação entre uma forma de realismo (que pode ser um realismo de entidades, ou um realismo nomológico, de relações ou de "leis") e de uma forma de racionalismo moderado, constitui a metafísica básica dos cientistas. Não há teoria física que não assuma previamente tanto a realidade objetiva quanto a cognoscibilidade do mundo físico. Antonio Augusto Passos Videira em Por que os físicos acreditam que as coisas existem: Breves comentários acerca das relações entre ciência e metafísica discute as diferentes formas de realismo adotadas pelos físicos filósofos.

"Existe um mundo exterior, isto é, independente do sujeito cognoscente, que por ele pode ser conhecido". Poderíamos sintetizar assim o credo metafísico fundamental do cientista na concepção de Planck. A filosofia seria o alfa e o ômega da ciência. Tanto o seu ponto de partida quanto seu objetivo final. "Sempre considerei a busca do absoluto a mais nobre tarefa da ciência" (PLANCK. 2012, p. 37). Em última instância, o que o cientista deseja fazer, o que motiva seu trabalho e lhe insufla ânimo, é chegar a uma compreensão da unidade e da ordem da natureza, participando assim, de uma busca filosófica que teve início na Grécia Antiga com 
os físicos ou cosmólogos a que nos acostumamos chamar de filósofos pré-socráticos. Tal busca requer renúncia, diz Planck, pois devemos almejar o absoluto, aquilo que é universal e imutável, que permanece idêntico a si mesmo, que se encontra subjacente no cerne das leis da natureza, conscientes, no entanto, de que podemos dele nos aproximar, mas jamais o alcançaremos por completo (Ibidem).

Essa ideia de que a física moderna seria herdeira do projeto intelectual de investigação da natureza iniciado pelos filósofos gregos é comum em Einstein (2008), Heisenberg (1995) e Schrödinger (1996). Desde os gregos, pensam Einstein e Infeld em A evolução da física, a ciência busca elaborar uma imagem unificada e ordenada do mundo, reduzindo a complexidade e pluralidade do mundo aparente a uma causa única e simples. Esse propósito é mesmo "o princípio subjacente a toda filosofia natural" (EINSTEIN; INFELD. 2008, p. 53). Como vimos, Einstein defende que o físico não deve deixar ao filósofo profissional a tarefa exclusiva de filosofar. O físico não tem escolha: principalmente nos momentos de crise dos fundamentos de sua ciência, filosofar se torna inevitável (EINSTEIN. 2017, p. 65).

Schrödinger, além de considerar Tales o primeiro cientista da história, assumindo a investigação filosófica como um novo estilo de pensamento que inaugura a ciência ocidental, pensa que o valor da ciência, sua razão de ser, é participar da busca por responder a grande questão filosófica posta por Plotino: “Quem somos nós?” (SCHRÖDINGER. 1996, p. 99). A ciência não é importante pelos resultados práticos, técnicos, de suas pesquisas. Tais resultados são desejáveis, mas secundários. A ciência importa, segundo Schrödinger, por nos dar uma cosmovisão racional, por aumentar nossa compreensão do mundo, e, por consequência, de nós mesmos. Por meio da ciência, participamos do logos, buscamos conhecer o cosmos e nosso lugar nele.

As ideias de Schrödinger ecoam nas de Heisenberg, que também nega que o valor da ciência seja utilitário e que a ciência deva se reduzir à técnica. Heisenberg assume a ciência como uma investigação filosófica da natureza, uma expressão de nosso assombro diante do universo infinito e suas leis. Para Heisenberg em Física Nuclear (1953) e outras obras, a ciência moderna seguiu ao longo de sua história, um curso aberto pelos filósofos gregos, e se constituiu fundamentada em alguns conceitos basilares, como o conceito de átomo, elaborado por Leucipo e Demócrito (HEISENBERG. 1953, p. 53).

A despeito da influência histórica do atomismo nas ciências da natureza, Heisenberg argumenta que a crise nos fundamentos da física provocada pela emergência da teoria quântica exigia o abandono do materialismo atomista e uma guinada rumo ao platonismo. "Independente 
da decisão última podemos afirmar agora que a resposta final [Para a questão "qual é a ontologia das partículas elementares?’] estará mais próxima dos conceitos filosóficos expressos, por exemplo, no Timeu de Platão do que dos antigos materialistas" (HEISENBERG. 2006, p. 26).

Abordamos a presença de um neoplatonismo no coração da física de Heisenberg em Teoria Quântica, Física Nuclear e Filosofia Grega: Ensaios sobre os físicos filósofos do século $X X$ (2017). Heisenberg pensava que as partículas elementares eram os produtos de puras simetrias matemáticas. Assim, o corpo material, mesmo enquanto uma simples partícula elementar, não é o fundamento último das estruturas físicas. Na estrutura da matéria há algo ainda mais básico do que a partícula elementar: são os princípios matemáticos, ou as simetrias que tais partículas "incorporam”, ou das quais as partículas "participam”. Tais princípios ou relações matemáticas é que são ontologicamente fundamentais, como os eidos, as formas puras da matéria (SILVA, 2017, p. 245). Os princípios matemáticos ou simetrias da física são "entes intelectivos", inobserváveis, isto é, realidades ideais ou entidades teóricas, objetos do intelecto, ao passo que as partículas elementares que se chocam em grandes colisores são suas expressões sensíveis, fisicamente mensuráveis, embora também não sejam diretamente observáveis. O que realmente é objeto da experiência sensível na física de partículas é sempre o fenômeno, a "manifestação" das partículas em eventos mensuráveis, não as partículas mesmas. Nunca se observa um próton ou um quark, mas seus efeitos em determinados arranjos experimentais.

Quando analisamos diversos dos maiores nomes da física, sempre encontramos uma atividade filosófica mais ou menos intensa. Essa afirmação é tão mais correta quanto mais afastados da segunda metade do século XX estivermos. A partir de algum momento entre os anos 1950 ou 1960 em diante o numero de físicos filósofos parece diminuir (ou mesmo se extinguir) bruscamente. Surgiram até mesmo os físicos aparentemente antifilosóficos, que desferiram ataques à filosofia, embora tenham sido muitas vezes inconsistentes. Feynman (2005) e Hawking (2011) escreveram sobre a irrelevância da filosofia para a física. No entanto qualquer estudo cuidadoso de suas obras é suficiente para demonstrar suas contradições, pois ambos, em algum momento, recorreram a algum filósofo ou ideia filosófica para discutirem suas teorias, assim como assumiram posições filosóficas (Silva, 2018). Cada um confirmou ao seu modo que a filosofia é inevitável para a física.

No Brasil, mesmo já na segunda metade do século XX, físicos como Schemberg e Leite Lopes produziram muita reflexão filosófica. Como mostramos em Um ideal de ciência: Leite Lopes e a história da física no Brasil (2019), Leite Lopes reconheceu que inúmeras são as dimensões filosóficas da ciência. Há uma dimensão metafísica, pois a ciência busca a verdade 
(E problematizar o que é a verdade ou qual teoria da verdade está em questão já é por excelência um problema filosófico). Uma dimensão ética, pois a ciência deve lutar pelo bem comum, e uma dimensão estética, pois contempla e cria formas belas. Certamente há um forte platonismo em tal concepção de ciência.

O tipo de físico antifilosófico mais nocivo à própria ciência, contudo, não é aquele que se atrapalha e se contradiz ao tentar negar a importância da filosofia para a física, mas aquele que reduz a física a uma atividade somente técnica e utilitária, ou seja, aquele que realmente faz da física uma tecnologia de produção de saberes "úteis", que serve acriticamente a finalidades práticas, conforme as demandas das corporações e dos Estados (que ele entende serem as "necessidades da sociedade").

Devemos frisar que essa não é uma opinião isolada. Como demonstramos em Qual é o valor da ciência? Metafísica e axiologia em tempos de Big Science e tecnociência (2017), muitos físicos, em diversas ocasiões, discutiram o tema, e externaram uma imensa preocupação com a redução do físico à categoria de "especialista". Inúmeros são os casos de cientistas que defenderam a dimensão filosófica da ciência e denunciaram que um cientista que não é capaz de filosofar e que apenas reproduz uma ciência a serviço de interesses utilitários coloca em risco os fundamentos e objetivos epistêmicos do próprio campo. William Whewell, Henri Poincaré, Pierre Duhem, e os já citados Einstein, Schrödinger e Heisenberg foram contundentes a esse respeito.

Em Ciência e humanismo, Schrödinger deixa claro que não se trata de uma crítica superficial e apressada a especialização. Conhecer de um modo cada vez mais meticuloso uma determinada área de pesquisa, sondar de um modo cada vez mais rigoroso cada detalhe de um objeto de investigação, é algo inevitável e mesmo desejável para o avanço do conhecimento. $\mathrm{O}$ real perigo não é a especialização em si, mas algo que geralmente a acompanha, que é a desconexão do especialista com a cultura, o isolamento do especialista em sua especialidade, apartando-o de um contexto intelectual mais amplo e rico. Ou seja, o perigo não é quando o cientista se torna especialista, mas quando, por ter se tornado especialista deixa de ser um intelectual, cessa de filosofar, e de buscar compreender qual é o lugar de sua especialidade no mundo da cultura. É nesse sentido que Schrödinger cita o filósofo espanhol José Ortega Y Gasset e seu conceito de homem-massa, para se referir ao "cientista-especializado" como "um representante típico da gentalha ignorante e estúpida (...) que põe em perigo a sobrevivência da verdadeira civilização". Esse homem-massa seria "um tipo de cientista sem precedentes na história" (SCHRÖDINGER. 1996, p. 100).

Perspectivas - Revista do Programa de Pós-Graduação em Filosofia da UFT - volume 5, n. 1 - 2020 
O físico técnico, des-intelectualizado, acrítico, preso de sua hiperespecialização, que já não pensa filosoficamente sobre os fundamentos de seu próprio campo de pesquisa, ou o busines maker que faz da ciência apenas um trampolim para seus projetos de ascensão financeira e política, tornam a física menos filosófica e, por isso, roubam-lhe sua cientificidade. Mas a física não é o que é por conta desses profissionais. Não são eles que escreveram seus grandes momentos.

O trabalho diário em épocas de "ciência normal" até pode ser predominantemente executado por esse espírito industrial, pelo hombre-masa de Ortega y Gasset, mas a "ciência extraordinária", para utilizar expressões kuhnianas, certamente é criação de livres pensadores que ousam filosofar.

Ao longo de grandes momentos da história da física, quando olhamos para Hypatia, Galileu ou Newton, para Maxwell ou Hertz, para Planck e Marie Curie, Einstein, Bohr e Heisenberg, ou para físicas e físicos, trabalhando diariamente nos centros de pesquisa, animados pela mesma busca por conhecimento que embalou esses grandes nomes, definitivamente não é o técnico, o hombre-masa que encontramos. Em todos esses casos, o que realmente vemos, é o físico filósofo. Se é possível fazer física sem filosofar? Vimos que a resposta para tal pergunta depende do que entendemos por física. Mas digamos que sim, que há física sem filosofia. O recurso à História da Ciência será fundamental para, em um passo além, verificarmos que essa física filosoficamente anêmica existe, mas, certamente, não é a física dos pioneiros da ciência moderna, tampouco a física dos fundadores da física contemporânea, assentada sob os pilares da mecânica quântica e da relatividade. Tanto a chamada Revolução Científica, quanto a criação de uma nova física na primeira metade do século XX foi obra de filósofos naturais e físicos filósofos.

\section{Agradecimentos}

Agradeço aos colegas do "Physikos - Estudos em História e Filosofia da Física e da Cosmologia", da FACH-UFMS, do Grupo de Pesquisa "Lógica, Linguagem e Ciência", da UFT e do Masterclass Internacional de Física de Partículas do Instituto de Física da UERJ, pelos diálogos constantes e inspiradores, que nos fazem refletir - prazerosamente - sobre as grandes questões da filosofia da física. A presença em grupos de pesquisa é fundamental para a participação em um ambiente de diálogo, debate e estudos. Como a pesquisa é uma prática coletiva, tais grupos nos mantêm ativos, nos apresentam a outros pesquisadores e abrem novas 
perspectivas, por isso, não poderia deixar de agradecer ao ECTS, "Estudos Sociais e Conceituais de Ciência, Tecnologia e Sociedade", do Departamento de Filosofia da UERJ, e ao TeHCo, "Grupo de Teoria e História dos Conhecimentos”, do Instituto de Física da USP. É no processo social de interação entre pesquisadoras e pesquisadores que nosso entendimento histórico das questões epistemológicas se forma paulatinamente. Assim educamos e vamos sendo educados uns pelos outros. Agradecemos também à equipe da Revista Perspectivas, pelo trabalho sério e competente e pela oportunidade que nos foi dada.

\section{Referências}

BOHR, Niels. Física atômica e conhecimento humano. Tradução de Vera Ribeiro. Rio de Janeiro: Contraponto, 1995.

BORN, Max; AUGER, Pierre; SCHRÖDINGER, Erwin; HEISENBERG, Werner. Problemas da Física Moderna. Trad. Gita. K. Guinsburg. São Paulo: Perspectiva: 2006.

DUHEM, Pierre. A Teoria Física: Seu objeto e sua estrutura. Tradução de Rogério Soares da Costa. Rio de Janeiro: Eduerj, 2014.

EINSTEIN, Albert. Como eu vejo o mundo. Tradução de H. P. de Andrade. Rio de Janeiro: Nova Fronteira, 1981.

EINSTEIN, Albert. Meus últimos escritos. Tradução de Maria Luiza X. de A. Borges. Rio de Janeiro: Nova Fronteira, 2017.

EINSTEIN, Albert. Sobre a Teoria Geral da Gravitação. In: Prêmios Nobel na Scientific American. Duetto: São Paulo, 2010.

EINSTEIN, Albert. Física e realidade. Rev. Bras. Ensino Fís. [online]. 2006, vol.28, n.1, p.922.

EINSTEIN, Albert; INFELD, Leopold. A Evolução da Física. Tradução de Giasone Rebuá. Rio de Janeiro: Zahar, 2018.

FEYNMAN, Richard. Física em 12 lições. Tradução de Ivo Korytowski. Rio de Janeiro: Ediouro, 2005.

HAWKING, Stephen; MLODINOV, Leonard. O grande projeto: novas respostas para as questões definitivas da vida. Tradução de Mônica Gagliotti Fortunato Friaça. Rio de Janeiro: Nova Fronteira, 2011.

HEISENBERG, Werner. A Parte e o Todo. Tradução de Vera Ribeiro.Rio de Janeiro: Contratempo, 1996. 
HEISENBERG, Werner. Física e Filosofia. Tradução de Jorge Leal Ferreira. Brasília: Editora Universidade de Brasília. 1995.

HEISENBERG, Werner. Nuclear Physics. London: Methuen \& CO. LTD.,1953.

HERTZ, Heinrich. Física Mecânica e Filosofia. Tradução de Gabriel Dirma Leão. Rio de Janeiro: Eduerj, 2012.

KUHN, Tomas. A Estrutura das Revoluções Científicas. Tradução de Beatriz Vianna Boeira e Nelson Boeira. São Paulo: Editora Perspectiva, 2001.

LOPES, José Leite. O valor da ciência e da tecnologia. In: Ciência e Desenvolvimento. Niterói: Tempo Brasileiro/Universidade Federal Fluminense, 1987.

PAULI, Wolgang. Escritos sobre Física y Filosofía. Madri: Editorial Debate S. A., 1996.

PLANCK, Max. Autobiografia científica e outros ensaios. Tradução de Estela dos Santos Abreu. Rio de Janeiro: Contraponto, 2012.

POINCARÉ. The Value of Science. New York: The Science Press. 1907.

SCHRÖDINGER, Erwin. A Natureza e os Gregos seguido de Ciência e Humanismo. Lisboa: Edições 70, 1996.

SILVA, Vinícius C. O grande projeto: novas respostas para as questões definitivas da vida. Argumentos, ano 10, n. 20 - Fortaleza, jul./dez. 2018.

SILVA, Vinícius C. Qual é o valor da ciência? Metafísica e axiologia em tempos de Big Science e Tecnociência. (Tese de Doutorado). Universidade do Estado do Rio de Janeiro (UERJ), Rio de Janeiro, 2017.

SILVA, Vinícius C. Teoria quântica, Física Nuclear e Filosofia Grega. Griot: Revista de Filosofia. v.15, n.1, junho/2017. p. 233-250.

SILVA, Vinícius C. Um ideal de ciência: José Leite Lopes e a história da física no Brasil. Ciência e sociedade, v. 6, p. 35-47, 2019.

SKLAR, Lawrence. Philosophy of Physics. Oxford: Oxford University Press, 1992.

VIDEIRA, Antonio Augusto P. Por que os físicos acreditam que as coisas existem: Breves comentários acerca das relações entre ciência e metafísica. Braga: Axioma, 2018. 